\title{
Kimura's Disease of the Nose: An Unusual Presentation
}

Leena Balachandar ${ }^{1}$ and Sana Khan ${ }^{2^{*}}$

${ }^{1}$ MS ENT, Consultant Columbia Asia Hospital, India

${ }^{2}$ MS ENT, Vydehi Institute of Medical Sciences and Research Centre, Bangalore, India

*Corresponding author: Sana Khan, Junior Resident, MS ENT, Vydehi Institute of Medical Sciences and Research Centre, Bangalore, India, Tel: 0091-9819679142; Email: sana.iak01@gmail.com

Received date: August 02, 2017; Accepted date: August 16, 2017; Published date: August 24, 2017

Copyright: (c) 2017 Balachandar L, et al. This is an open-access article distributed under the terms of the Creative Commons Attribution License, which permits unrestricted use, distribution, and reproduction in any medium, provided the original author and source are credited.

\begin{abstract}
Kimura's disease is a chronic inflammatory condition of unknown etiology. Kimura et al. in 1948 first reported this disease usually presents in Asian males in their $2^{\text {nd }}$ to $4^{\text {th }}$ decade as a mass in the head and neck region. Coexisting lymphadenopathy, eosinophilia and raised serum IgE levels, also renal involvement in some cases. Our patient is a 49 years old male with swelling on his nose following trauma, with elevated AEC and IgE levels. Excision biopsy revealed it to be kimura's disease. Kimura's presenting as a soft tissue swelling in nose without any nodal involvement is not common in the Indian subcontinent. We present this case for its rarity.
\end{abstract}

Keywords: Kimura; AHLE; Subcutaneous mass; Eosinophilia; IgE; Lymphadenopthy

\section{Introduction}

Kimura's disease is an allergic chronic inflammatory condition of unknown etiology. Kimura et al. in 1948 reported it in literature titled "On the unusual granulation combined with hyperplastic changes of lymphatic tissue" after which this entity became widely known as Kimura's disease [1]. Usually presenting as a mass in the region of the head and neck with coexisting lymphadenopathy, eosinophilia and raised serum IgE levels. Renal involvement is its only systemic manifestation. This disease is typically present in Asian individuals in their $2^{\text {nd }}$ to $4^{\text {th }}$ decade of life $(70-80 \%)[2,3]$. Treatment options range from conservative observation for asymptomatic patient to surgical excision and radiotherapy for symptomatic patients.

\section{Case Report}

A 49-year-old male patient presented to our OPD with swelling on the right side of his nose. The swelling appeared consequent to trauma 10 years before presentation. Initially small and diffuse, it progressively increased overtime to its present size $3 \times 4 \mathrm{~cm}$. It is a painless swelling associated with occasional watering from the right eye. There was no history of weight loss, low grade fever or night sweating. Medical, surgical and family histories were noncontributory. Physical examination revealed a $3 \times 4 \mathrm{~cm}$ swelling extending just above the right supraorbital rim to $1 \mathrm{~cm}$ below medial canthus (Figure 1). Skin over the swelling was normal except for hyperpigmentation (Figure 2). Patient had elevated levels of eosinophils $-21 \%$, absolute eosinophil count- 239.4 cells $/ \mathrm{mcL}$ and serum IgE - $2541.11 \mathrm{iu} / \mathrm{ml}$. Renal involvement was ruled out with normal Renal Function tests and USG KUB. A computed tomography (CT) scan disclosed enhancing mass lesion at inner canthus of right eye $16 \mathrm{~mm} \times 20 \mathrm{~mm} \times 27 \mathrm{~mm}($ Ap $\times \operatorname{tr}$ $\times$ cc) HU 68 plain and HU 99 post contrast (Figure 3). No evidence of erosion of underlying bone. Orbit was pushed laterally. Brain study was normal. Based on the CT an excisional biopsy was performed (Figure 4). Intraoperative, a curvilinear incision placed over the swelling. Mass was nonencapsulated, firm in consistency, with irregular margins adherent to the skin and underlying muscles pushing the orbit laterally but not adherent to the orbit (Figure 5). Highly vascular in nature. Histopathology revealed Gross grey brown tissue measuring $1.8 \mathrm{~cm} \times$ $1.5 \mathrm{~cm} \times 0.7 \mathrm{~cm}$. Cut surface shows gray brown areas. (2P) external surface inked. Microscopically fibrocollagenous and fibro muscular tissue devoid of lining epithelium with stroma containing reactive lymphoid aggregates with mixed inflammatory cell infiltrate rich in eosinophils. Proliferating blood vessels noted lined by plump endothelial cells surrounded by lymphoid cells and eosinophils. Sections negative for granulomas and malignancy.

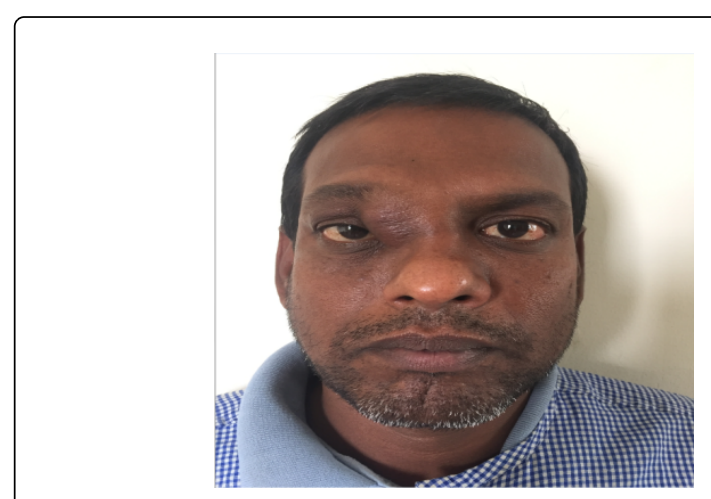

Figure 1: Pre-operative image- $3 \times 4 \mathrm{~cm}$ swelling extending just above the right supraorbital rim to $1 \mathrm{~cm}$ below medial canthus. 


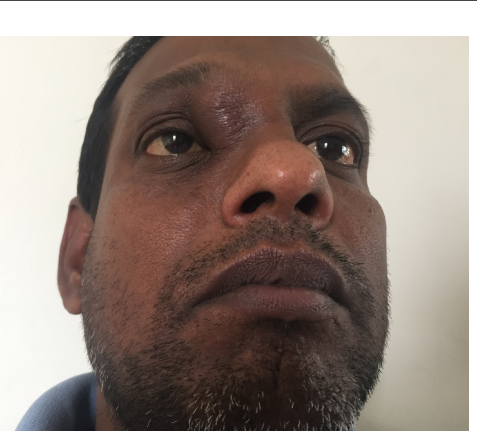

Figure 2: Pre-operative diffuse swelling on the right side of the nose showing hyperpigmentation.

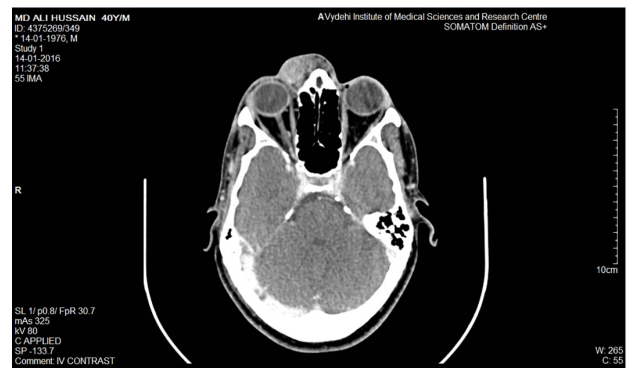

Figure 3: CE CT showing enhancing mass lesion at inner canthus of right eye $16 \mathrm{~mm} \times 20 \mathrm{~mm} \times 27 \mathrm{~mm}(\mathrm{ap} \times \operatorname{tr} \times \mathrm{cc})$ hu 68 plain and hu 99 post contrast.

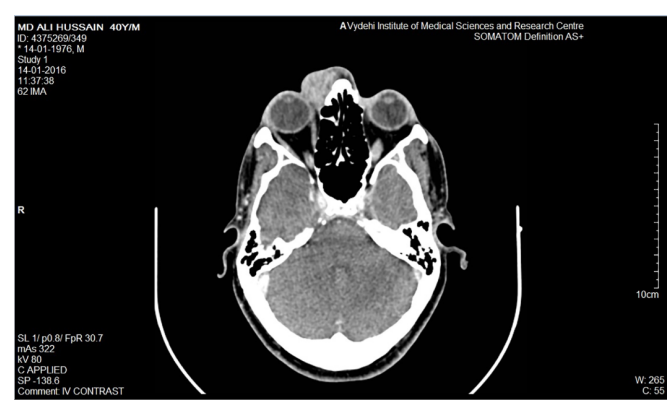

Figure 4: CT showing enhancing mass lesion at inner canthus with no bony erosion.

\section{Discussion}

Kimura's disease (KD) is an uncommon, benign, chronic inflammatory disorder of unknown etiology [4]. Kimura's disease typically presents as a painless subcutaneous swelling in the preauricular and submandibular regions, though involvement of the orbit, eyelids, epiglottis, axilla, forearm, groin or popliteal region has been reported [5]. Kimura's is classified as a benign reactive process, with its etiopathogenesis varying from allergic reactions, infections, and autoimmune reactions with an aberrant immune reaction [6]. Herein we present a patient with atypical manifestation of Kimura's with no renal impairment and a rare site of occurrence. An article published in the Journal of Oral and Maxillofacial Pathology carried out a Pub Med search in 2013 using the title 'Kimura's disease' and cases where the diagnosis was 'ALHE' or 'epitheloid haemangioma' were excluded, found that 20 cases of Kimura's disease have been reported in the Indian population including their case [7]. Earlier Kimura's and AHLE have been used interchangeably as two entities of the same spectrum. However, the Current evolving concepts suggest that the two conditions are distinct with relevant distinguishing features which help in correct diagnosis, knowing the course of disease and prognosis.

The patient presented in this study is an Indian male in his $4^{\text {th }}$ decade with a painless swelling post trauma but with the absence of lymphadenopathy. Histologically, shows features of overlap between Kimura's and AHLE, although predominantly Kimura's disease. There were reactive lymphoid aggregates with mixed inflammatory cell infiltrate rich in eosinophils, which is a feature of Kimura's disease, However, the presence of vascular channels with plump endothelial cells is a distinctive feature of AHLE (Figure 6). Characteristically, there is accompanying Peripheral blood eosinophilia, raised serum $\operatorname{IgE}$ levels and Raised AEC levels suggestive of Kimura's disease. AHLE is known to affect women in the $2-3^{\text {rd }}$ decade without peripheral eosinophilia. CT showed an enhancing mass lesion suggestive of Haemangioma (Figure 7). A syringe test demonstrated that there was no obstruction in the lacrimal passage. There was no history of eyelid surgery. Facial nerve function was unaffected. Renal ultrasound evaluation and kidney function tests were normal. The rarity of this case is because of the occurrence in non-Orientals involving the nose with no lymphadenopathy and grossly elevated IgE levels with marked eosinophilia. To the best of our knowledge one other case Praveer Kumar Banerjee et al. reported a case of a 54-year-old male resident of Bhilai, India presented swelling of the nose since 4 years and a similar swelling behind his right ear since 1 year, the diagnosis established to be Kimura's through histopathological examination in April 2016 [8] (Figure 8).

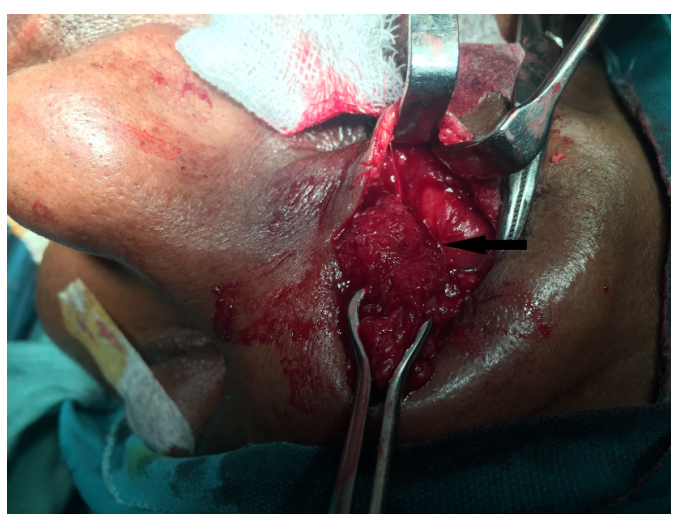

Figure 5: Intra operative mass was nonencapsulated, firm in consistency, with irregular margins adherent to the skin and underlying muscles pushing the orbit laterally but not adherent to the orbit. 


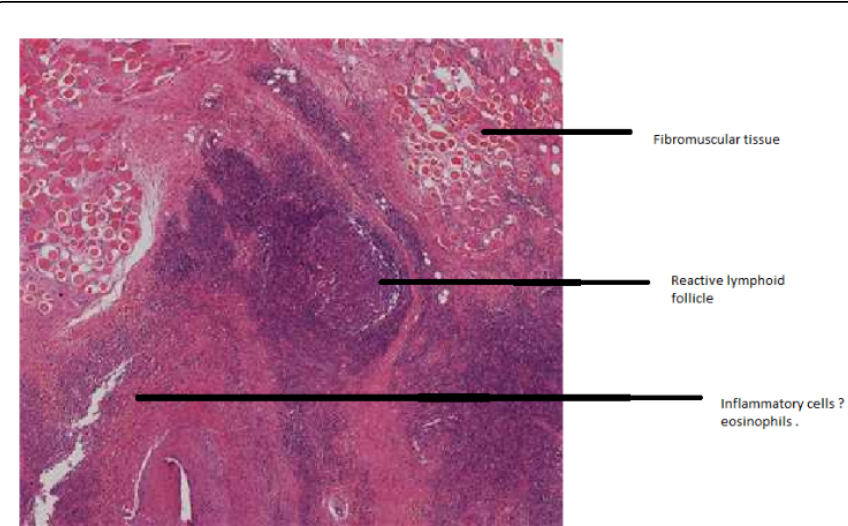

Figure 6: Microscopically fibrocollagenous and fibro muscular tissue devoid of lining epithelium with stroma containing reactive lymphoid aggregates with mixed inflammatory cell infiltrate rich in eosinophils proliferating blood vessels noted lined by plump endothelial cells surrounded by lymphoid cells and eosinophils. No signs of granulomas or malignancy.

Recurrence has been reported in up to $25 \%$ of patients treated with surgical excision alone [9]. Given these statistics, it would be advisable to keep the patients under review for at least 3 years after initial treatment. Given that Kimura's Disease is a nonmalignant disease, radiotherapy is generally limited to cases not compliant with surgery or those who have failed medical therapies [10]. Nephrotic syndrome and renal impairment are important sequelae which may affect up to $60 \%$ of patients [11]. FNAC is inadequate to diagnose the disease, most often an open biopsy is required for tissue biopsy [12]. Primary treatment for Kimura's is surgical excision. Additional medical therapy including regional or systemic steroid therapy, cytotoxic therapy or radiation [13]. Steroids such as Cyclosporine when administered systemically, they arrests the progression of the disease due to its effects on Th2 lymphocytes [14].

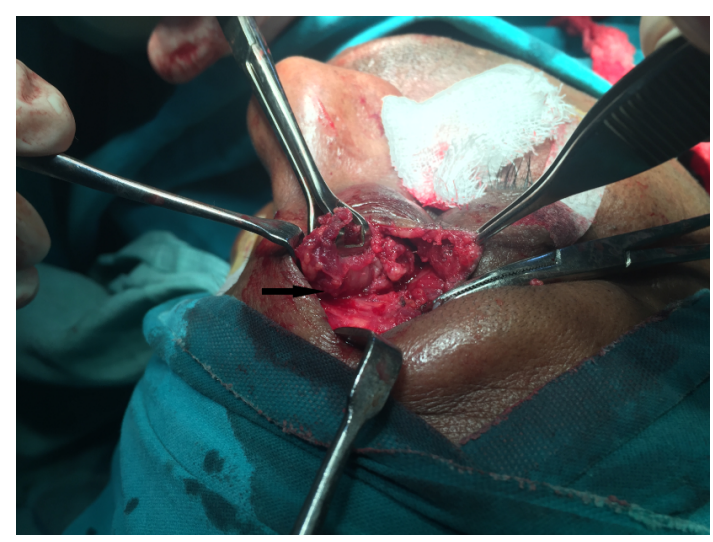

Figure 7: Mass with irregular margins and highly vascular.

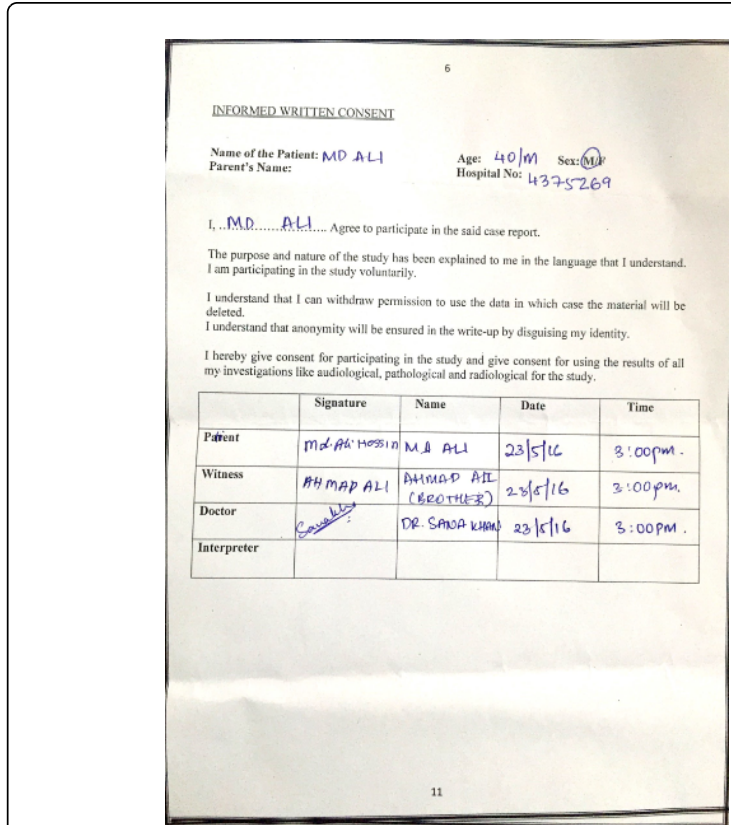

Figure 8: Patient consent.

\section{Conclusion}

The Diagnosis of Kimura's diseases was based on raised IgE and histopathological reports. The treatment goals are to preserve function and cosmetics while keeping the patient in follow up for recurrence and the sequel. This case is reported to make the surgeons aware of such a rare occurrence in an unusual site.

\section{Acknowledgements}

We would like to thank the patient for giving us his consent to share his details. We thank our colleagues from the Department of ENT and Head and Neck Surgery who provided insight and expertise that greatly helped us in reporting this case.

We thank Dr. Sathish Kumar, Professor and Head of Department at Vydehi institute of medical sciences and research Centre for his support and valuable comments that greatly improved the manuscript. We are also immensely grateful to the department of Pathology for their help.

\section{References}

1. Kimura T, Yoshimura S, Ishikawa E (1948) On the unusual granulation combined with hyperplastic changes of lymphatic tissue. Trans Soc Pathol Jpn 37: 179-180.

2. Li TJ, Chen XM, Wang SZ, Fan MW, Semba I, et al. (1996) Kimura's disease: a clinicopathologic study of 54 Chinese patients. Oral Surg Oral Med Oral Pathol Oral Radiol Endod 82: 549-555.

3. Ranka SR, Rajput A, Kantharia CV (2004) Kimura's disease. Indian J Otolaryngol Head Neck Surg 56: 43-45.

4. Mitsui M, Ogino S, Ochi K, Ohashi T (1996) Three cases of eosinophilic lymphfolliculoid granuloma of the soft tissue originating from the parotid gland. Acta otolaryngol Suppl 522: 130-132. 
Citation: Balachandar L, Khan S (2017) Kimura's Disease of the Nose: An Unusual Presentation. J Allergy Ther 8: 262. doi: 10.4172/2155-6121.1000262

Page 4 of 4

5. Bobinskas AM, Chandu A, Nastri AL (2015) Kimura's disease: an uncommon cause of head and neck masses with potentially serious sequelae. J Surg Case Rep 2015: rjv131.

6. Park SW, Kim HJ, Sung KJ, Lee JH, Park IS, et al. (2012) Kimura disease: CT and MR imaging findings. AJNR Am J Neuroradiol 33: 784-788.

7. Sah P, Kamath A, Aramanadka C, Radhakrishnan R (2013) Kimura's disease- An unusual presentation involving subcutaneous tissue, parotid gland and lymph node. J Oral Maxillofac Pathol 17: 455-459.

8. Banerjee P (2016) Kimura's Disease- An Unusual Presentation. Iran J Otorhinolaryngol 28: 237-240.

9. Karaman E, Isildak H, Ozdilek A, Sekercioglu N (2008) Kimura disease. J Craniofac Surg 19: 1702-1705.

10. Armstrong WB, Pena F, Allison G, Kim JK (1998) Kimura's disease: two case reports and a literature review. Ann Otol Rhinol Laryngol 107 1066-1071.
11. Noel N, Meignin V, Rosenstingl S, Ronco P, Boffa JJ, et al. (2009) Nephrotic syndrome associated with immune thrombocytopenia revealing Kimura's disease in a non-Asian male. NDT plus 2: 452-454.

12. Viswanatha B (2010) Kimura disease: an unusual cause of head and neck masses. Report of 2 cases. Ear Nose Throat J 89: 87-90.

13. Sun QF, Xu DZ, Pan SH, Ding JG, Xue ZQ, et al. (2008) Kimura disease: review of the literature. Intern Med J 38: 668-672.

14. Kaneko K, Aoki M, Hattori S, Sato M, Kawana S (1999) Successful treatment of Kimura's disease with cyclosporine. J Am Acad Dermatol 41: 893-894. 